\title{
Genotypic Variations in Growth Response and P-acquisition Efficiency by Spring Wheat Cultivars Exposed to Sparingly Soluble P-sources
}

\author{
M. Shahbaz Akhtar ${ }^{1,2 *}$, Yoko Oki ${ }^{1}$, Yoshitaka Nakashima ${ }^{1}$ \\ ${ }^{1}$ Department of Environmental Management Engineering, Graduate School of Environmental \& Life Science, \\ Okayama University, Okayama, Japan. \\ 2 Department of Soil \& Environmental Sciences, University College of Agriculture, University of Sargodha, \\ Sargodha, Pakistan. \\ * Corresponding author. Tel.: +81-90-86071981; email: drakhtarms@gmail.com \\ Manuscript submitted October 12, 2017; accepted January 16, 2018. \\ doi: 10.17706/ijbbb.2018.8.3.187-194
}

\begin{abstract}
To estimate genetic variability in growth characteristics and phosphorus acquisition efficiency from sparingly soluble P-sources; four genetically diverse spring wheat cultivars, categorized as 'P-efficient and low P-tolerant (class-I), and P-inefficient and low P-sensitive (class-II) cultivars' based on P-efficiency characteristics in a hydroponic study, were grown in a sand culture in order to evaluate their relative performance in a glass house experiment. Pre-treated, cleaned uniform sized seeds of cultivars were sown in 4-kg capacity pots containing yamazuna sand with negligible available P. P-treatments were (i) (LP)-control treatment without any applied P (ii) (AP)- $\mathrm{NH}_{4} \mathrm{H}_{2} \mathrm{PO}_{4} @ 200 \mu \mathrm{M} \mathrm{P} \mathrm{kg}-1$ as an adequate P-supply, (iii) (TCP)-tri-calcium phosphate $\left(\mathrm{Ca}_{3}\left(\mathrm{PO}_{4}\right)_{2} @ 0.5 \mathrm{~g} \mathrm{~kg}^{-1}\right.$, and (iv) (RP)-rock phosphate @ $0.5 \mathrm{~g} \mathrm{~kg}^{-1} \mathrm{of}$ sand. Tri-calcium phosphate and rock phosphate were sparingly soluble P-sources containing negligible P soluble in water. Biomass accumulation by plants, P-concentration and uptake in roots and shoots of plants, phosphorus stress factor and P-efficiency characteristics were differed in tested cultivars indicating sufficient genetic diversity in wheat cultivars. Biomass and growth parameters were significantly correlated with plant P-parameters indicating that $\mathrm{P}$ taken up by the plants from sparingly soluble P-sources was accumulated into the plant biomass. Class-I cultivars exhibited better performance than class-II cultivars indicating their better ability to scavenge $\mathrm{P}$ at all $\mathrm{P}$ levels.
\end{abstract}

Key words: Sources with sparingly soluble P, P-efficiency, P-stress factor, spring wheat cultivars.

\section{Introduction}

Phosphorus $(\mathrm{P})$ is the $2^{\text {nd }}$ important macronutrient for optimum growth and development of plants. Low phosphorus availability is a major constraint and a limiting factor for crop production [1]. Phosphorus availability is challenged in tropics and subtropics due to its notorious fixation, interaction, sorption and complexation in soils, with certain ions and metals coupled with slow diffusion of fully oxidized orthophosphate (Pi) [2]-[4]. P scarcity is very critical in tropics that are characterized with highly weathered soils [5]. Exogenous application of soluble $\mathrm{P}$ fertilizers is the first choice to correct $\mathrm{P}$ deficiency stress. However, use of soluble P fertilizers is also questionable in terms of economics and efficiency, and their excessive use can result in environmental pollution such as eutrophication and hypoxia in the surrounding water bodies [6], [7]. Furthermore, global phosphate reserves are rapidly diminishing; 
especially reserves of rock phosphate with good quality are estimated to be depleted within the coming decades [8]. In addition to the depletion issue of rock phosphate reserves, high prices of P fertilizers and poor infra structure is another challenge to address the $\mathrm{P}$ deficiency issue in developing countries. This scenario questions the feasibility of current fertilizer use in emerging and developed countries [5] and impels us to revise our strategy to increase P efficiency by minimizing further P inputs. To achieve this goal, P-efficient genotypes that can explore better and exploit the below ground resources well by modifying their rhizosphere and root architecture are desirable traits [5], [9]. Better plant P-uptake and utilization plays an essential role in determining the final crop production [10]. Hence, to develop/select plants that can scavenge and utilize $\mathrm{P}$ in more efficient manner from sparingly soluble phosphorus is one of the strategies to minimize the use of P fertilizers [11].

Plants manifest genetic variability to combat this challenge of low P-availability by displaying different adaptive and rescue mechanisms at inter and intra-specific level to regulate phosphate acquisition and utilization. In this context, plants evolve highly specialized traits (physiological, morphological, biochemical and molecular mechanisms) that enable the plants to uptake and use phosphorus from the environment [12]. The integration of crop cultivars efficient in P-acquisition with improved P-management is extremely essential for enhancing P efficiency and crop production. Development/selection of plant cultivars with better phosphorus acquisition and phosphorus use efficiency from P sources with sparingly soluble $\mathrm{P}$ will add more $\mathrm{P}$ into agricultural ecosystems by scavenging $\mathrm{P}$ from sparingly soluble $\mathrm{P}$ sources.

To estimate genetic diversity in plant growth characteristics and phosphorus acquisition and use efficiency from sparingly soluble P-sources (tri-calcium phosphate and rock phosphate), contrasting spring wheat (Triticum aestivum) cultivars, classified as 'class-I and class-II cultivars', were grown in order to compare their relative performance in a glass house sand culture experiment.

\section{Experimental Protocol}

\subsection{Plant Material and Growth Environment}

Healthy seeds of four spring wheat cultivars were collected from Pakistan Agriculture Research Council (PARC), Islamabad, and Ayub Agricultural Research Institute (AARI), Faisalabad, Pakistan. Cultivars were categorized as 'class-I cultivars (Mairaj-08 and BWP-97) (low P-tolerant and P-efficient) and class-II (Fareed-06 and Lasani-08) (low P-sensitive and P-inefficient) cultivars' based on their P-efficiency characteristics from a hydroponic study. Pre-treated, clean, healthy and uniform seeds were sown in yamazuna sand with negligible available P. Demineralized water was applied in order to ensure optimum moisture amount for germination of seeds and establishment of seedlings. Modified nutrient solution was applied to culture media low in available nutrients. The elemental concentration of nutrient solution was; (in mM): $\mathrm{NH}_{4} \mathrm{NO}_{3}$ (1), $\mathrm{KNO}_{3}(2), \mathrm{MgSO}_{4} .7 \mathrm{H}_{2} \mathrm{O}(0.5), \mathrm{K}_{2} \mathrm{SO}_{4}(0.5), \mathrm{Ca}\left(\mathrm{NO}_{3}\right)_{2} .4 \mathrm{H}_{2} \mathrm{O}$ (2) and (in $\mu \mathrm{M}$ ): $\mathrm{H}_{3} \mathrm{BO}_{3}(25)$, $\mathrm{ZnSO}_{4} .7 \mathrm{H}_{2} \mathrm{O}$ (2), $\mathrm{Fe}(\mathrm{III})$-EDTA (50), $\mathrm{H}_{2} \mathrm{MoO}_{4}$ (0.5), $\mathrm{CuSO}_{4} .5 \mathrm{H}_{2} \mathrm{O}$ (0.5), $\mathrm{KCl}(50), \mathrm{MnSO}_{4} \cdot \mathrm{H}_{2} \mathrm{O}$ (2). To maintain concentrations of macro and micro nutrients taken up by the plants, nutrient solutions were replenished at one week interval. Experimental units used in the experiment are represented in Fig. 1.

\subsection{Phosphorus Treatments}

To estimate differential responses in growth and phosphorus acquisition from sparingly soluble P-sources, phosphorus was applied in pots as (i) (LP)-control treatment without any applied P (ii) (AP)- $\mathrm{NH}_{4} \mathrm{H}_{2} \mathrm{PO}_{4} @ 200 \mu \mathrm{M} \mathrm{P} \mathrm{kg}{ }^{-1}$ as an adequate P-supply, (iii) (TCP)-tri-calcium phosphate $\left(\mathrm{Ca}_{3}\left(\mathrm{PO}_{4}\right)_{2} @\right.$ $0.5 \mathrm{~g} \mathrm{~kg}^{-1}$, and (iv) (RP)-rock phosphate @ $0.5 \mathrm{~g} \mathrm{~kg}^{-1}$ of sand. TCP and RP are sparingly soluble P sources having almost negligible P soluble in water. Four spring wheat cultivars were grown in each P-level with three repeats of each cultivar by using factorial CRD (completely randomized design). 


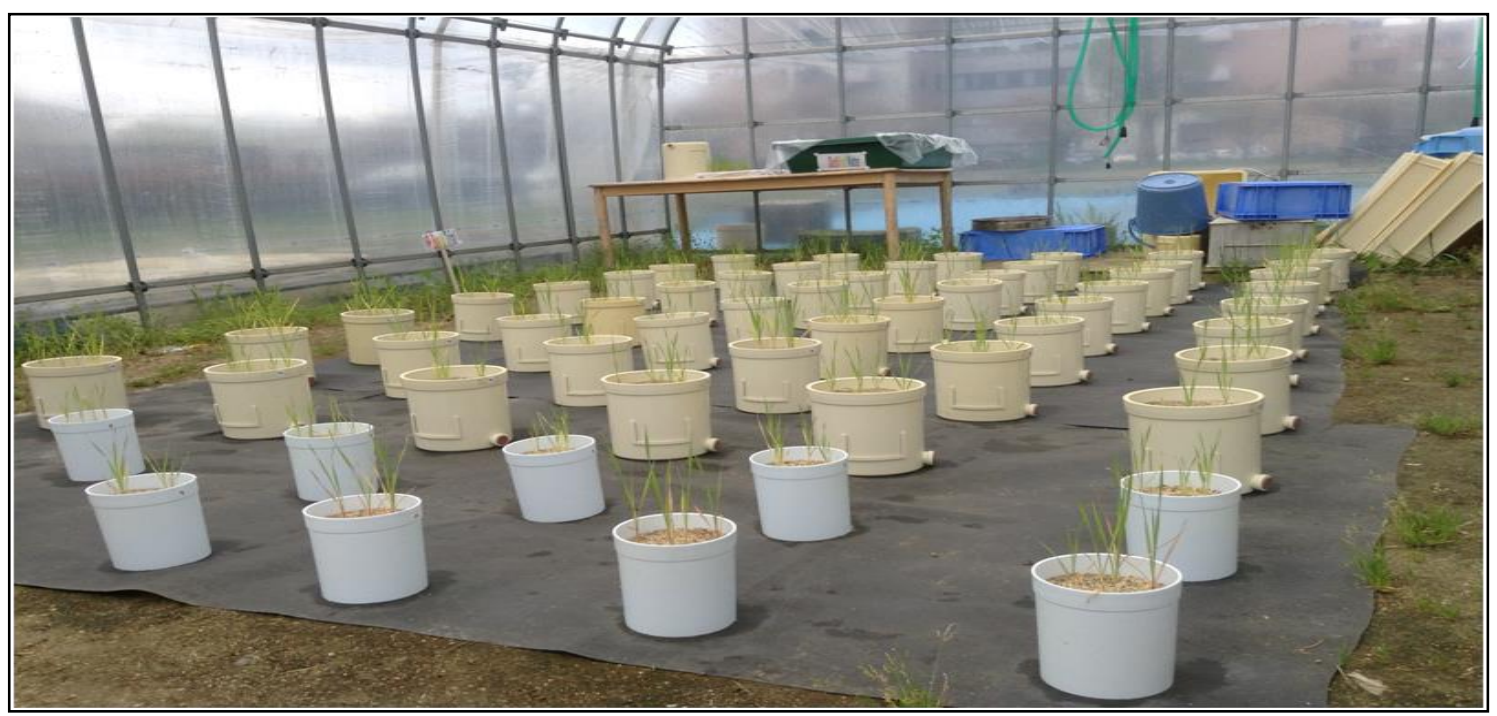

Fig. 1. Experimental units used to evaluate wheat cultivars in a green house experiment.

\subsection{Biomass and Phosphorus Assay}

Wheat plants were harvested at 28 days after seed sowing to investigate plant growth and related parameters of the plant growth. After harvesting, plants were divided into plant parts (roots and shoots). Plant were rinsed twice in demineralized water in order to remove the attached grains of TCP or RP with roots, removed moisture with tissue paper sheets, and samples were put in craft paper bags. A forced-air driven oven was used to dry plant samples at $80^{\circ} \mathrm{C}$ for $48 \mathrm{hr}$. The dried plant samples were well ground (40-mesh) so that the samples can pass through a $0.42 \mathrm{~mm}$ screen. The samples were then digested in $5 \mathrm{ml}$ of $2 \mathrm{~N} \mathrm{HCl}$ after making dry ash for $7 \mathrm{hr}$ at $550^{\circ} \mathrm{C}$ in a muffle furnace. In order to ensure the complete digestion of the samples, solutions having $5 \mathrm{ml}$ of $2 \mathrm{~N} \mathrm{HCl}$ were evaporated at $80{ }^{\circ} \mathrm{C}$ until pellets were obtained. The obtained pellets were again dissolved in $5 \mathrm{ml}$ of $2 \mathrm{~N} \mathrm{HCl}$ and mixed thoroughly. Then, the filtration of the solutions was carried out by discarding the first portions of the obtained filtrate. Phosphorus concentrations ([P]s) in plant samples were measured by using a spectrophotometer (Hitachi, U-1100) by developing blue color (blue color method) using spectrophotometery technique. Phosphorus uptake (mg plant ${ }^{-1}$ ) was estimated on plant dry matter (DM) basis by multiplying [P]s with DM in plant parts, and on the entire plant basis by summing up the P-contents values in the shoot and root of the plants.

$$
\text { Phosphorus uptake }\left(\mathrm{mg} \mathrm{plant}^{-1}\right)=([\mathrm{P}])\left(\mathrm{mg} \mathrm{g}^{-1}\right) \mathrm{X} \text { DM }\left(\mathrm{g} \mathrm{plant}^{-1}\right)
$$

\subsection{Phosphorus Efficiency Characteristics}

Phosphorus stress factor (\% PSF) for shoot dry matter (SDM) (g plant ${ }^{-1}$ ) was estimates as under:

$$
\% \operatorname{PSF}=\left(\mathrm{SDM}_{(\mathrm{AP})}-\mathrm{SDM}_{(\mathrm{LP} / \mathrm{TCP} / \mathrm{RP})} / \mathrm{SDM}_{(\mathrm{AP})}\right) \mathrm{X} 100
$$

Phosphorus utilization efficiency (PUE) was estimated according to Siddiqi and Glass [13], as under:

$$
\text { PUE }\left(\mathrm{g} \mathrm{DM}^{2} \mathrm{mg}^{-1} \mathrm{P}\right)=\mathrm{DM}\left(\mathrm{g} \mathrm{plant}^{-1}\right) /[\mathrm{P}]\left(\mathrm{mg} \mathrm{g}^{-1} \mathrm{DM}\right)
$$

Phosphorus efficiency ratio (PER) was estimated as according to Gerloff and Gabelman [14], as follows: 


$$
\text { PER }\left(\text { g DM mg }^{-1} \mathrm{P}\right)=\mathrm{DM}\left(\mathrm{g}_{\text {plant }}{ }^{-1}\right) / \mathrm{P} \text { uptake }\left(\mathrm{mg} \mathrm{plant}^{-1}\right)
$$

Phosphorus efficiency (PE) (relative growth) was calculated as under:

$$
\mathrm{PE}=\left(\mathrm{DM}_{(\mathrm{LP} / \mathrm{TCP} / \mathrm{RP})} / \mathrm{DM}_{(\mathrm{AP})}\right) \times 100
$$

\subsection{Statistical Analysis}

Standard statistical procedures were used to analyze the data [15]. Means of the treatments were used for correlation coefficient $(\mathrm{r})$ values and presented with \pm SE. $P<0.05$ was considered statistically significant.

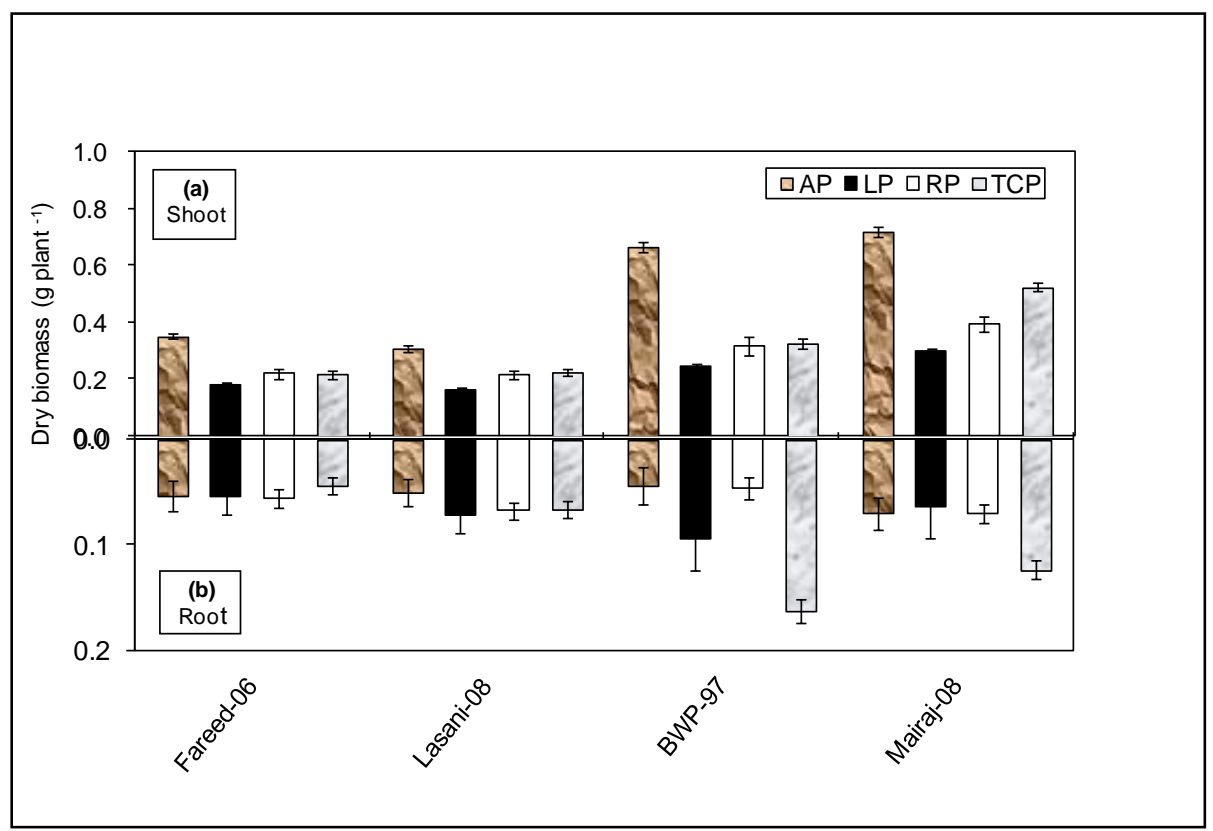

Fig. 2. Dry biomass of spring wheat cultivars exposed to stress (sparingly soluble P), low and sufficient P; Mean are presented with \pm SE.

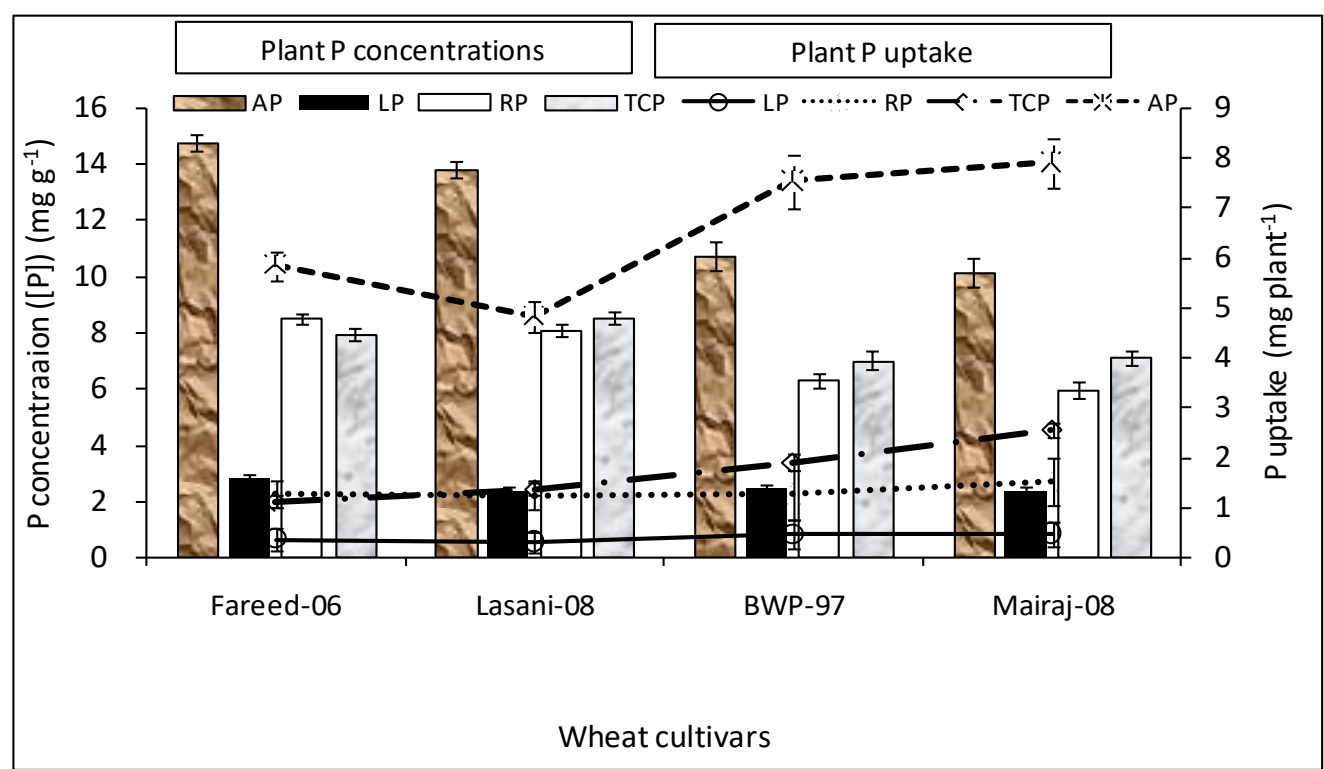

Fig. 3. Phosphorus concentrations and phosphorus contents of spring wheat cultivars exposed to stress (sparingly soluble P), low and adequate P. 


\section{Results and Discussion}

\subsection{Accumulation of Plant Biomass, $P$ concentrations and $P$ contents}

Spring wheat cultivars showed genetic variations in biomass accumulation. P stress affected plant dry matter (DM) production in plant shoots and roots significantly at low P levels in the present study (Figs. 2a-b). In the present study, cultivars grown with stress/low levels of P produced less DM than those grown with adequate $P$ (control treatment), which was in agreement with earlier studies in wheat [16]-[18] and in Brassica [19] crop cultivars. The class-II cultivars (Fareed-06 and Lasani-08) exhibited more reduction in biomass in comparison with the class-I cultivars (Mairaj-08 and BWP-97), and this decline in biomass of the plants highlights more sensitivity of the class-II cultivars exposed to P-stress deficiency environment. Class-I cultivar marij-08 produced highest biomass when exposed to sparingly soluble P sources indicating its better performance to grow under low $\mathrm{P} / \mathrm{P}$-stress environment without reducing growth considerably. These results indicated that the class-I cultivars could be the promising choice under P-starvation.

Plant P concentrations ([P]s) and P contents in 28-day old wheat plants exposed to various P levels are shown in Fig. 3. Phosphorus sources and spring wheat cultivars showed significant interactive and main effects on plant $[\mathrm{P}] \mathrm{s}$ and total phosphorus contents. Averaged over cultivars, $[\mathrm{P}] \mathrm{s}$ were less in plants exposed to low $\mathrm{P}, \mathrm{Ca}_{3}\left(\mathrm{PO}_{4}\right)_{2}$ and rock phosphate, respectively, compared to adequate $\mathrm{P}$ treatment. The wheat cultivars exhibited significant differences in plant $\mathrm{P}$ uptake after 28 days of exposure to $\mathrm{P}$ treatments.

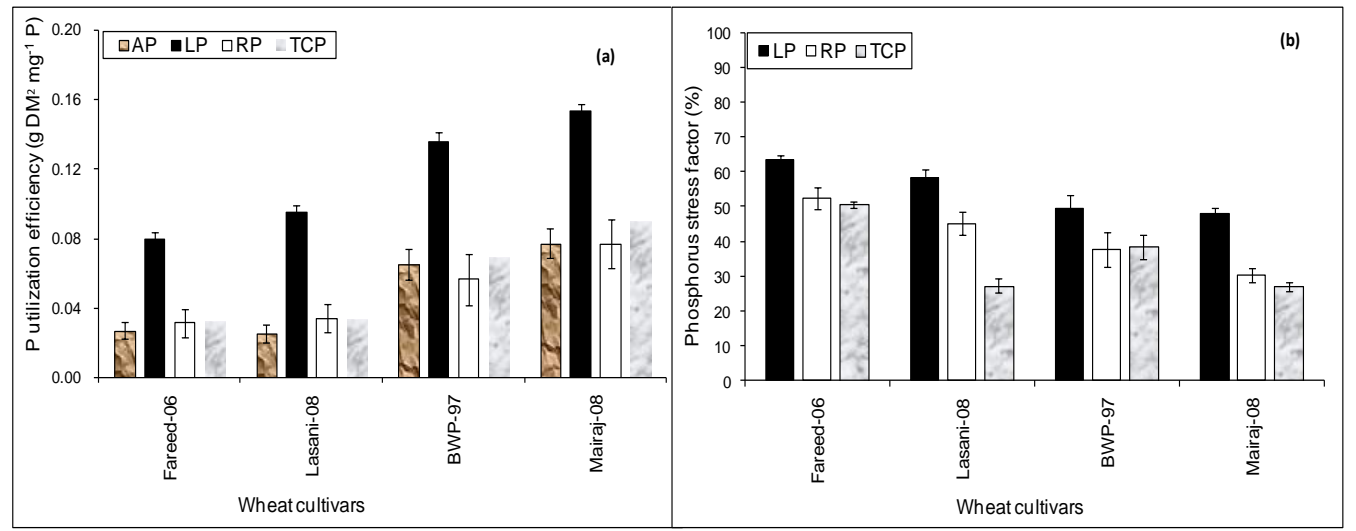

Fig. 4. Phosphorus utilization efficiency and P stress factor of cultivars exposed to stress, low \& adequate P.

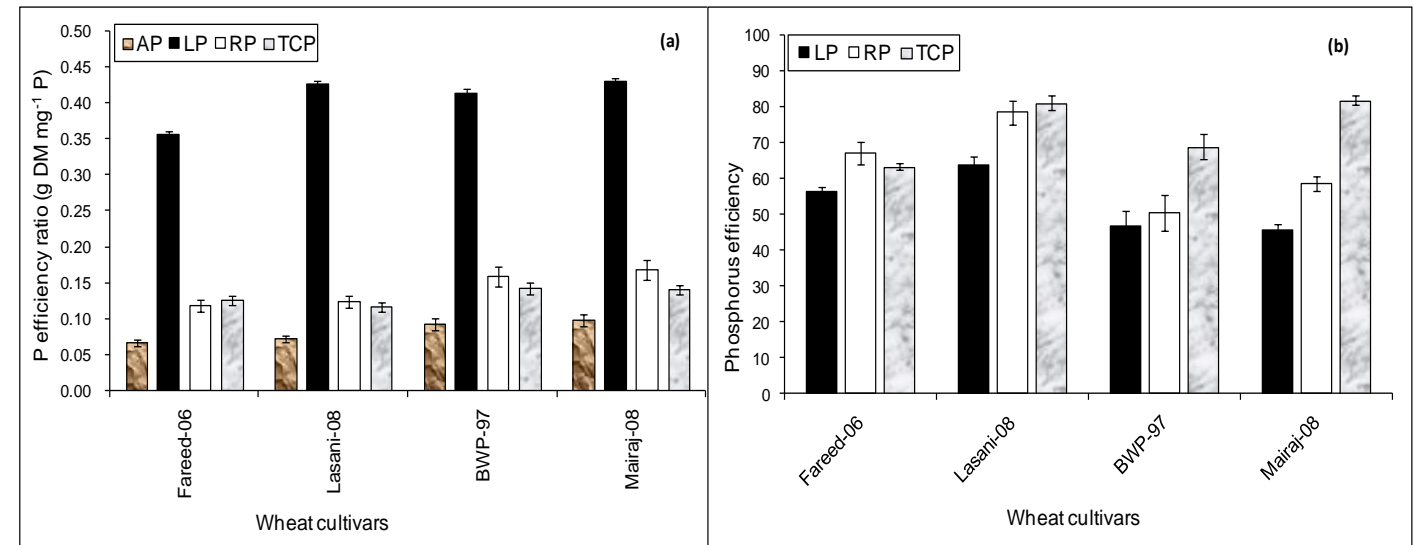

Fig. 5. Phosphorus efficiency ratio and P efficiency factor of cultivars exposed to stress, low and high P.

\subsection{P Efficiency Characteristics}

Different Phosphorus efficiency characteristics [i.e., P utilization efficiency (PUE), P stress factor (PSF), P 
efficiency ratio (PER), and P efficiency (PE)] are presented in Figs. 4-5. The wheat cultivars and P levels exhibited considerable variations in terms of $\mathrm{P}$ efficiency related parameters under P-stress environments. High nutrient efficiency is the ultimate consequence of better $\mathrm{P}$ acquisition and utilization efficiency. The class-I wheat cultivars exhibited high PUE values compared to the class-II wheat cultivars (Fig. 4a) indicating their better ability to utilize the absorbed P. Figure $4 \mathrm{~b}$ depicts considerable diversity of relative tolerance amongst wheat cultivars grown with low P, rock phosphate and tricalcium phosphate. Class-I cultivars exhibited lesser PSF than the mean value under P-stress environments. The class-I cultivars also presented high PER and PE values compared to the class-II cultivars (Fig. 5a-b) indicating that these cultivars have the better ability for P-acquisition than the other cultivars.

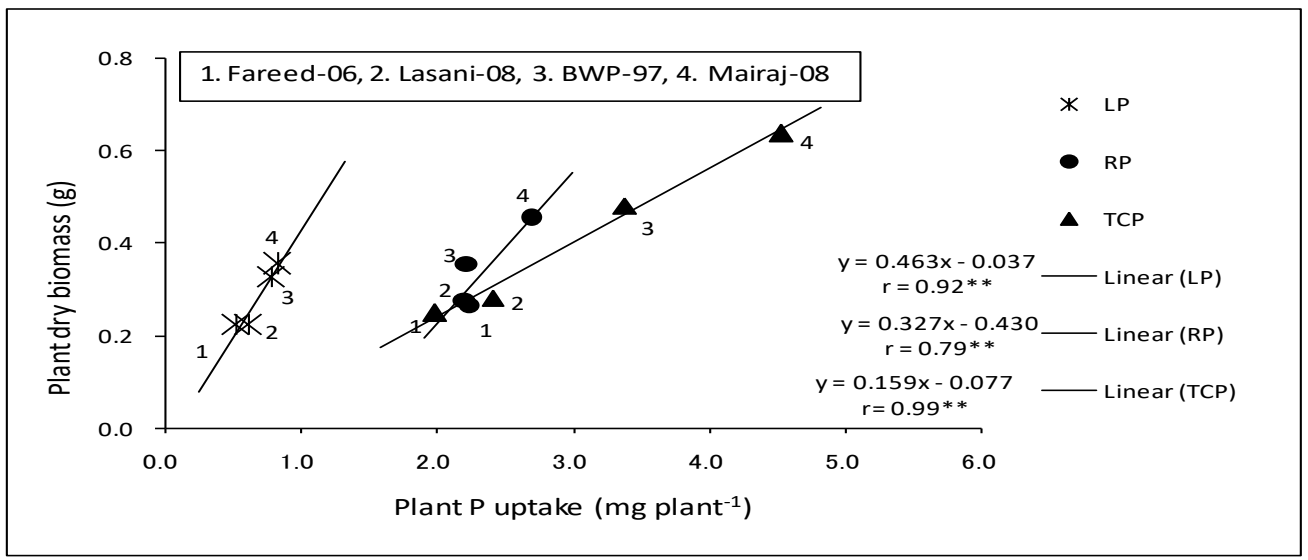

Fig. 6. Relationship between P uptakes vs. biomass of wheat cultivars exposed to P different treatments.

Results obtained in the present study highlighted that the P-efficient cultivars exhibiting high PE, PUE, and PER, produced higher biomass, and, thus, these cultivars could be the best option for low P or P-stress soil environments. Plant $\mathrm{P}$ uptake was significantly correlated with dry matter showed that P-efficient/low $\mathrm{P}$ tolerant cultivars accumulated higher plant biomass than P-inefficient/P sensitive cultivars (Fig. 6). This differential growth behaviour of spring wheat cultivars is due to their different potential to acidify the rhizospheric vicinity and to solubilize, uptake and use $\mathrm{P}$ from sparingly soluble rock phosphate and $\mathrm{Ca}_{3}\left(\mathrm{PO}_{4}\right)_{2}$. These results are in agreement with earlier study [20] showing that rhizosphere acidification by root induced $\mathrm{H}^{+}$-efflux can enhance $\mathrm{P}$ acquisition by solubilizing $\mathrm{P}$ from sparingly soluble $\mathrm{P}$ sources.

\section{Conclusion}

Tested spring wheat cultivars display genetic variations in growth behavior and phosphorus acquisition when they were exposed to stress (sparingly soluble P), low and sufficient $\mathrm{P}$ levels. The growth and $\mathrm{P}$ acquisition parameters were significantly correlated. More biomass accumulation and better P efficiency characteristics by 'class-I cultivars' than the 'class-II cultivars' under low P/P stress, can be attributed to their better phosphorus use (P acquisition and utilization) from sparingly soluble $\mathrm{P}$ forms present in the root environment. By deploying $\mathrm{P}$ efficient/low $\mathrm{P}$ tolerant cultivars in combination with sparingly soluble P-sources can ensure cropping on sustainable basis and will also mitigate the risks of $\mathrm{P}$ related environmental pollution.

\section{Acknowledgment}

The investigation was financially supported by JSPS (Grant in aid for JSPS fellows, No.26•03908).

\section{References}


[1] Xiurong, W., Shen, J., \& Liao, H. (2010). Acquisition or utilization, which is more critical for enhancing phosphorus efficiency in modern crops? Plant Science, 179, 302-306.

[2] Vance, C. P., Uhde-Stone, C., \& Allan, D. L. (2003). Phosphorus acquisition and use: critical adaptations by plants securing a nonrenewable resource. New Phytologist, 157, 423-457.

[3] Hinsinger, P. (2001). Bioavailability of soil inorganic P in the rhizosphere as affected by root induced chemical changes: a review. Plant and Soil, 237, 173-195.

[4] Akhtar, M. S., Nishigaki, M., Oki, Y., Adachi, T., Nakashima, Y., Murtaza, G., Aziz, T., Sabir, M., Saifullah, Maqsood, M. A., Zia-ur-Rehman, M., Wakeel, A., Nakamoto, Y., \& Hartwig, C. (2013). Solubilization and acquisition of phosphorus from sparingly soluble $\mathrm{P}$ sources and differential growth response of Brassica cultivars exposed to phosphorus stress environment. Communications in Soil Science and Plant Analysis, 44, 1242-1258.

[5] Hinsinger, P., Betencourt, E., \& Bernard, L., et al. (2011). P for two, sharing a scarce resource: Soil phosphorus acquisition in the rhizosphere of intercropped species. Plant Physiology, 156, 1078-1086.

[6] Carpenter, S. R. (2005). Eutrophication of aquatic ecosystems: Bistability and soil phosphorus. Proceedings of the National Academy of Sciences (pp. 10002-10005).

[7] Tilman, D., Fargione, J., Wolff, B., D’Antonio, C., Dobson, A., Howarth, R., Schindler, D., Schlesinger, W. H., Simberloff, D., \& Swackhamer, D. (2001). Forecasting agriculturally driven global environmental change. Science, 292, 281-284.

[8] Cordell, D., Drangert, J-O., \& White, S. (2009). The story of phosphorus: Global food security and food for thought. Global Environmental Change, 19, 292-305.

[9] Lynch, J. P. (2007). Roots of the second green revolution. Australian Journal of Botany, 55, 493-512.

[10] Shen, J., Yuan, L., Zhang, J., Li, H., Bai, Z., Chen, X., Zhang, W., \& Zhang, F. (2011). Phosphorus dynamics: From soil to plant. Plant Physiology, 156, 997-1005.

[11] Hammond, J. P., Braodley, M. R., White, P. J., King, G. J., Bowen, H. C., Hayden, R., Meacham, M. C. , Mead, A., Overs, T., Spracklen, W. P., \& Greenwood, D. J. (2009). Shoot yield drives phosphorus use efficiency in Brassica oleracea and correlates with root architecture traits. Journal of Experimental Botany, 60, 1953-1968.

[12] Hammond, J. P., Braodley, M. R., \& White, P. J. (2004). Genetic responses to phosphorus deficiency. Annals of Botany, 94, 323-332.

[13] Siddiqi, M. Y., \& Glass, A. D. M. (1981). Utilization index: A modified approach to the estimation and comparison of nutrient utilization efficiency in plant. Journal of Plant Nutrition, 4, 289-302.

[14] Gerloff, G. C., \& Gabelman, W. H. (1983). Genetic basis of inorganic plant nutrition. Encyclopedia of Plant Physiology, 453-480.

[15] Steel, R. G. D., \& Torrie, J. H. (1980). Principles and Procedures of Statistics (2 ${ }^{\text {nd }}$ ed.). New York: McGraw Hill.

[16] Akhtar, M. S., Oki, Y., Nakashima, Y., Adachi, T., \& Nishigaki, M., (2016). Phosphorus stress induced differential growth and phosphorus acquisition and use efficiency by spring wheat cultivars. Communications in Soil Science and Plant Analysis.

[17] Kosar, H. S., Gill, M. A., Rahmatullah, A. T., Akhtar, M. S., \& Imran, M. (2002). Solubilization of tricalcium phosphate by different wheat genotypes. Pakistan Journal of Agricultural Sciences, 39, 273-277.

[18] Manske, G. G. B., Ortiz-Monasterio, J. I., Van Ginkel, M., González, R. M., Rajaram, S., Molina, E., \& Vlek, P. L. G. (2000). Traits associated with improved P-uptake efficiency in CIMMYT's semi dwarf spring bread wheat grown on an acid Andisol in Mexico. Plant Soil, 221, 189-204.

[19] Akhtar, M. S., Nishigaki, M., Oki, Y., Adachi, T., Nakamoto, Y., \& Hartwig, C. (2014). Phosphorus stress induced variations in growth behavior, and P efficiency among Brassica cultivars grown with sparingly 
soluble P sources. Communications in Soil Science and Plant Analysis, 45, 1995-2017.

[20] Akhtar, M. S., Oki, Y., \& Adachi, T. (2009). Mobilization and acquisition of sparingly soluble P-sources by Brassica cultivars under P-starved environment II. rhizospheric $\mathrm{pH}$ changes, redesigned root architecture and Pi-uptake kinetics. Journal of Integrative Plant Biology, 51, 1024-1039.

M. Shahbaz Akhtar is an assistant professor at the Department of Soil \& Environmental Sciences, UCA, University of Sargodha, Pakistan. Presently, he is also working as a researcher at the Department of Environmental Management Engineering, Graduate School of Environmental and Life Science, Okayama University, Japan. His research specialized in soil and environmental sciences, eutrophication, phytoremediation \& phytoextraction of toxic metals and pollutants, soil chemistry and plant nutrition, plant responses under abiotic stress environments, environmental and lithosphere management, and problems of soil-water-environment triangle \& their smart solutions.

He graduated from University of Agriculture, Faisalabad, Pakistan in 2000. Then he pursues his study in the same university for M.Phil degree in Soil \& Environmental Sciences in 2002. In 2008, He got his Ph.D. degree in Soil \& Environmental Sciences form Lithosphere Rehabilitation Lab., Department of Environmental Management Engineering, Graduate School of Environmental \& Life Science, Okayama University, Japan.

Dr. Akhtar published numerous papers in journals and in proceedings. He started his academia in university since 2003. From 2003 to 2008, he was lecturer and assistant professor of soil \& Environmental Sciences, Department of Soil \& Environmental Science, University of Agriculture, Faisalabad, Pakistan. From 2008 to 2010 and 2013-2015, he worked as JSPS researcher and from 2010 to 2013 as a Researcher at the Department of Environmental Management Engineering, Graduate School of Environmental \& Life Science, Okayama University, Japan before starting JSPS fellowship at the same institute in 2013. He joined the Department of Soil \& Environmental Sciences, UCA, University of Sargodha, Pakistan as an assistant professor in 2012.

Yoko Oki is an eminent professor at the Department of Environmental Management Engineering, Graduate School of Environmental and Life Science, Okayama University, Japan. Presently she is also working as a vice president of Okayama University, Japan. Prior to this position, she performed her duties as a dean (2007-2008) and vice dean (2005) of the Faculty of Environmental Science and Technology, Graduate School of Environmental and Life Science, Okayama University, Japan in addition to different other administrative positions in her esteem career. She also worked as a researcher at University of Florida in 1984. She was director of Environmental Management Center in 2010 and director of libraries, Okayama University, Japan from 2013 to to-date. Dr. Oki also worked as a principal investigator and coordinator in different research projects.

Her main research area is function and management of vegetation. She is leading the group of Vegetation Management Engineering Lab. Dr. Oki published numerous papers in journals and proceedings. She has been awarded different prestigious awards and honors for her excellent and outstanding contribution in research and academic activities.

Yoshitaka Nakashima is an assistant professor at the Department of Environmental Management Engineering, Graduate School of Environmental and Life Science, Okayama University, Japan. His main research area is effect of environmental stress on growth response and reproduction of Iris pseudacoru. Dr. Nakashima also published numerous papers in journals and proceedings during his academic career. 